\title{
Awareness of Food Labeling among Consumers in Groceries in Al-Ain, United Arab Emirates
}

\author{
Sidiga Washi \\ Department of Nutrition and Health, \\ United Arab Emirates University, Al-Ain, PO box 17555, United Arab Emirates \\ Tel: 971-50-132-8960 E-mail: sidigaw@uaeu.ac.ae.
}

This research was sponsored by the Research Affairs at United Arab Emirates University (UAEU) Grant \#: 02-04-6-11/09.

Received: October 3, 2011 Accepted: November 8, $2011 \quad$ Published: February 1, 2012

doi:10.5539/ijms.v4n1p38 URL: http://dx.doi.org/10.5539/ijms.v4n1p38

\begin{abstract}
Over the last few decades, the prevalent UAE food retail industry setup showed the changing food consumption patterns of the UAE population. Diet-related health problems are increasing in UAE as a result of obesity and other factors. Therefore, nutritional labeling becomes important to provide consumers with information that can be used to make informed and healthier food choices. 1200 consumers $(54.3 \%$ were women) were interviewed while shopping at various grocery stores in AL-Ain city; UAE to assess their knowledge; attitudes and practices using a questionnaire. Consumer's responses showed general awareness for reading the food label (89.5\%); however; they read basic information like production and expiry dates. In summary; increased diet related diseases in UAE may be related to increased consumption of pre-packaged foods and inadequate awareness on use of food labeling information. This study has an educative health and nutrition implications to help consumers make an informed choice when buying pre-packaged foods.
\end{abstract}

Keywords: Food labeling, UAE, Consumer's knowledge/awareness, Nutrition, Health, Pre-packaged foods

\section{Introduction}

Food labels are found to be a very important public health tool that is used to promote a balanced diet; and hence enhance the public health and wellbeing. Food labels information assists consumers to better understand the nutritional value of food and enables them to compare the nutritional values of similar food products and to make healthy informed food choices based on the relevant nutrition information (AL Tamimi \& company, 2004). In addition; it is particularly useful for people who are on special diets (e.g. people suffering from diabetes or high blood lipid) to select suitable foods for their health conditions. As consumers are becoming increasingly aware of the relationship between diet and disease; their demand for nutrition information increases.

Most of the pre-packaged food products; imported and locally manufactured; are now provided with nutrition information on their food labels. There are many important diet related -public health problems and diseases such as poor nutrition; obesity high blood pressure; cancers, diabetes; osteoporosis and cardiovascular diseases. The World Health Organization reported that dietary factors accounted for approximately 30\% of cancers in industrialized countries. Therefore, nutrients are vital to humans for growth and maintenance of good health (WHO/FAO, 2003).

Globalization, which has its impact on consumers and their countries all over the world, required necessary actions from countries to prove that their manufactured products; including food; are able to compete in the open market. Food labeling encourages the food manufacturers to improve the nutrient profile of their products beside; the trade can formulate the relevant marketing strategies to attract potential consumers. This will result in a benefiting situation for both; the consumers and the manufacturers (AMEinfo.com, 2008).

Cost-benefit analyses suggest that saving in health care costs is relatively greater than the costs incurred by mandatory labeling. Overseas experience has shown that nutrition labeling can have positive impact on food 
consumption patterns; save healthcare costs and type 2 diabetes is increasing each year. With the introduction of mandatory nutrition labeling many lives could be saved each year (Hawkes, 2004).

The use and impact of the current labeling reflect that consumers perceive themselves as knowledgeable regarding its use. The parts of the label read most frequently were the calorie; fat; sugar; sodium and fiber contents. They use attributes such as serving size; ingredient list; the \% daily values; health and nutrient claims; price; and brands when making their food purchasing decisions (McLean, 2001; Whitney \& Rolfes, 2005). Many consumers feel confident that they understand how to read labels and prefer using a food label than relying on their own knowledge (Godwin et al., 2006).

Assessing the consumer's nutrition knowledge level about dietary fats and cholesterol and their attitudes towards selecting foods based on their nutritive value rather than avoidance of risk is important. Their knowledge and attitudes were positively correlated with their educational level. Those with higher education are usually more receptive to nutrition and health education and use the equal value approach to risk and benefits instead of risk avoidance (Levy et al., 2001; Himbachi \& Stokes, 2003).

The last decade has seen development in food processing which necessitated the development of new labeling provisions to facilitate informed consumer choice. The belated recognition by legislators and industry that food allergy is a major food safety issue and can be life threatening; has led to the need for label warnings about the presence of major food allergens. Considerable interest in the effect of labels on food product demand is found. Labeling statements may reflect new information about attributes that allows consumers to make different choices; consumers' assessment of information in labels may be affected by reference points (Blanchfield, 2000). With the aggressive rising of food retail sector in the Arabian Gulf region including UAE and the increase in building of more food mega marts type stores; the food retail industry prevalent shows changing in food consumption patterns of the population that results in a focus shift towards processed food; retailing supermarket chains as well as increased investments in the food industry at the country level (www.reportbuyer.com, 2007; Gian Report, 2008; Al Tamimi \& Company, 2004).

Never the less; there were few attempts to address the consumer's awareness of nutritional aspects of food labeling use in the region. It was evident that even though consumers were aware of the importance of reading food labels; they regarded information on manufacturing date; expiry date and content of the package as the most important information on labels (Washi, 2002). This might be attributed to the fact that most of the foods manufactured or repackaged in that region have labels lacking many of the nutrition information required by the American standards such as nutrition facts; serving size; special characteristics; health claims; special usage and health warnings (Washi, 2001).

With the rising concerns about the interrelationship between nutrition; health and life style among UAE population; this study has aimed to assess the consumer's knowledge about the important information on the labels and to whether those labels will assist them to take right decisions when buying pre-packaged foods. Therefore; it is important to enlighten UAE consumers about the importance of reading the food labels. This study also reflects on some of the consumers' views on these labels; and what they want to see on them. In addition; as no similar study was previously conducted in UAE; this study will provide new and recent data related to the use of food labels by consumers in UAE which are necessary to then put in place public health recommendations and programs to improve consumers' behaviors towards better use of the information on the food label as well as enlightening the food authorities to consider the nutritional aspects of the food label for better nutrition labeling regulations and nutritional status of UAE population.

\section{Methods and materials}

This descriptive cross-sectional study has assessed Al-Ain grocery shopper's knowledge; attitudes and practices towards food labeling. The study was conducted in Al-Ain major Food Market Centers (Carrefour in Jimi and AlBawadi Malls Mega Mart, Al-Ain Co-operative supermarket, and Lulu Hypermarket) during September-December, 2009.

\subsection{Sample size and selection}

Calculation of the sample size (SS) was based on the total population of AL-Ain city $(374,000)$. After all necessary approvals were obtained (from the Research Affairs of UAE University and the administration of the selected grocery stores); a sample of 1200 subjects, who represent $3.2 \%$ of Al Ain total population were conveniently selected from shoppers at the major AL-Ain grocery stores (www.wikipedia/alain/population, 2009). Five major groceries representative of the major geographic sections (north; south; east and west) of AL-Ain were randomly selected as locations for this study. 
The 1200 subjects who have agreed to be interviewed by 6 trained data collectors have signed consent forms to participate in this study. Upon their agreement and by using a validated questionnaire that was previously developed by the researcher, pilot tested for face validity and used in a similar study conducted by the researcher in Saudi Arabia (Washi, 2001). The twelve items questionnaire was piloted again and minor modification was made; demographic; and food label behavior data were collected. In addition; information on what consumers were like to see on the food label was also collected.

\subsection{Data collection}

\subsubsection{Demographics}

The gender; social status; nationality and level of education of the consumers were assessed.

\subsubsection{Knowledge; attitude and practice}

The objectives of the consumer's survey were to assess their knowledge about food labeling and if they practice reading and understanding the information on the food label and what kind of information they are looking for or would like to see on the food label. An awareness score was computed using the consumer's judgment on the importance of 13 items listed on the consumer's survey. Accordingly; the level of awareness was classified into 3 categories as follow: high level of awareness if the consumer selected 9-13 items; middle level of awareness if the consumer selected 5-8 items; and low level of awareness if the consumer selected 4 items and less.

\subsubsection{Statistical analysis}

Data were analyzed using SPSS Inc.; version 17.0; Chicago; IL. The chi-square test was performed as appropriate to assess if there were statistically significant differences between the demographic characteristics with regard to label use. Statistical significance was set at 0.05 .

\section{Results}

More than half of the sample was female (54.3\%). In comparison to other major cities in UAE; Alain is known to have more nationals. However; many of the Emirati grocery shoppers who were approached have declined to respond to the data collectors; which resulted in less than one third of the sample as Emirati respondents (31.7\%). Those from other nationalities are more Arabs than other nations with Egyptians; Syrian; and Jordanian constitute the three largest percentages of respondents respectively. A total of $69.5 \%$ were university graduates reflecting higher educational level among grocery shoppers interviewed. The level of education of the sample was reflected on their occupations; as $34.7 \%$ are government employees; $17.0 \%$ are professionals; while $14.1 \%$ are working in the private sector and $13.6 \%$ are students. Housewives are around $15.6 \%$ of the sample which give the opportunity to target them for an educational program on food labeling. Few are retired (1.3\%).

About $67.9 \%$ of the sample is married; and about $73.1 \%$ of the consumers interviewed have children in the family. Presence of children in the family is positively affecting consumers when making decisions on food purchase as they read more the food label $\left(\mathrm{X}^{2}=21.356 ; \mathrm{df}=13 ; \mathrm{P}=0.012\right)$ (see table 1 below). This finding resembles the findings of the 2006 study by the American Center for Food safety where families with children are keener to read food labels (Al Tamimi \& Company (2004).

As seen in Fig. 1 and when consumers interviewed were asked if they buy prepackaged food and read the food label; $91.6 \%$ stated that they buy prepackaged foods. About 89.5\% stated that they read the food label (Fig.2); this high percentage of those who read the food label may be related to the high educational level (Table1) of the consumers in this study $\left(\mathrm{x}^{2}=173 ; \mathrm{df}=12 ; \mathrm{P}=0.001\right)$. Similar result was found by Saltos and others in USA in 1994; which showed a positive statistical correlation between the level of education and consumer's interest in reading the food label (Saltos et al., 1994).

Twelve items were identified as information which might relatively be available in the food label and the consumers may be looking at when buying the food packages. Interviewees were given an option to add any item missed from the list; and were asked to identify what they were looking at on the food label (Fig.3).

The analysis showed that the majority of the consumers (85.6\%) look to see the information about expiry dates; followed by production dates $(70.3 \%)$. As stated before; this information is found in all prepackaged food according to the requirements of the UAE Metrology Standards (Emirates Standardization and Metrology Authority, 2007).

Around $53.3 \%$ want to see special characteristics stated followed by details of package contents (48.5\%). The package size was found to be the least important; followed by instructions for preparation. 
Consumers were asked to prioritize the most 3 types of information they are looking to see on the food label. As reflected in table 2; the first important choice they want to see is the expiry date (39\%); followed by the production date $(27.0 \%)$. The Second choice was found to be again the expiry date $(27 \%)$ while the country of manufacturing was selected by $(12.5 \%)$ of the sample.

Significant relationships were found between genders; level of education and looking for special characteristics on the food label. More women $(\chi 2=9.97 ; \mathrm{df}=11 ; \mathrm{P}=0.002)$ and highly educated $((\chi 2=18.04 ; \mathrm{df}=13 ; \mathrm{P}=0.002)$ are looking for such information. Education level was also correlated with looking to see health claims on the food label $\left(\chi^{2}=11.69 ; \mathrm{df}=12 ; \mathrm{P}=0.001\right)$.

More women are also looking for information for special use on the food label than men $(\chi 2=5.12 ; \mathrm{f}=11 ; \mathrm{P}=0.001)$. Significant correlations were also found between special use of the package content and education level $(\chi 2=6.78$; $\mathrm{df}=17 ; \mathrm{P}=0.005) ;$ social status $(\chi 2=12.21 ; \mathrm{df}=3 ; \mathrm{P}=0.007)$ and having children $(\chi 2=13.71 ; \mathrm{df}=11 ; \mathrm{P}=0.001)$.

On the other hand; the health warning showed significant correlations with gender $\left(\chi^{2}=5.12 ; \mathrm{df}=9 ; \mathrm{P}=0.024\right)$ and education level $(\chi 2=10.99 ; \mathrm{df}=10 ; \mathrm{P}=0.001)$. Males and the less educated care less about presence of health warnings on the package (Table 2).

Consumers were also asked about what they want to see on the food label if they would buy a pre-package food (Table 3). More than half (58.8\%) would like to see all information (manufactory; expiry dates and validity dates; nutritive value of food in addition to the health claims and the health warning). A small percentage of $18.9 \%$ want to see the manufactory and expiry dates; while $11.4 \%$ want to see health claims and health warning beside those who want to see the nutritive value of food (9.2\%) (Table3).

Most of the studies done in Western countries and North America aimed to compare between the preferences of consumers for the design and presentation of information on the food label as shown in the studies of Saltos (1994) and Yetly and Lewis (1992). Consumer's views around the food label were similar; in terms of the necessity to be simple; explaining element such as calories; sodium; fat; proteins; iron; calcium; carbohydrates; especially with the increased awareness about the interrelationship between food and peoples' health.

Consumers' preferences presented in Table 3 gave the same results and explains the most important information consumers want to see included on the food label; from among the 13 items they responded to in Table 4 . The results ensured the importance of including the expiry dates as a first preference and a second preference for many consumers. The production date came as a second preference.

To measure the consumer's Level of awareness about the information on the food label; a measuring score was constructed. The previously constructed 13 items were considered. If the consumer agree with any item then 1 point to be given; 0 point if the consumer didn't see the importance of the item. Accordingly; Table 4 shows that $42 \%$ of the consumers have middle level of awareness while $37 \%$ with low level of awareness. According to the score computed only $21 \%$ of the consumers have high level of awareness despite the fact that most of the consumers interviewed were of higher level of education (69.5\% are university graduates) and among the $30 \%$ who are below university education; $25.5 \%$ are of secondary and intermediate education. This indicates that a lot of effort has to be exerted by nutritionists to raise the level of awareness of the consumers about the importance of reading and using information on the food label.

On the other hand; higher level of awareness was found among female (23.62\%) than male consumers (18.61\%) reflecting significant gender differences $\left(x^{2}=29.986 ; d f=13 ; P=0.005\right)$ (Table 5). No significant relationship was found between high level of awareness and high level of education.

\section{Discussions}

This part of the study aimed at defining the needs of Alain shoppers (consumers) in the first place and their views in general about the prepackaged food label and whether it suits their prospects and provided them with the required information to enable them to make the right decisions to purchase the prepackaged food products.

The convenient selection of the studied sample has a positive impact in getting a wide range of consumer's responses; in addition; the sample composed of almost equal presentation for both genders which enabled the studying of the impact of gender. The sample also included a considerable percentage of housewives; which gave a chance to see the views of a group from this sector; as it was difficult to get their views otherwise. Their presence in Food Market centers also reflects their interest to select their own food based on certain preferences; and this enables targeting them with nutrition awareness programs about the food label. Students are another group found as consumers among the sample interviewed; they could also be targeted in area of awareness rising around the food label. 
Although production and expiry dates are mandatory items on all food labels; the study reflected the increased importance given by the consumers to the necessity of including them on the food label. This indicates that the consumers are always concerned about the risks which might appear from consuming expired foods that may cause diseases. Nutritionists can work on this area to help consumers to understand the benefits and risks of foods; and hence enable them to evaluate the information available and accordingly take the right purchasing decisions based on nutritional awareness rather than avoiding risks only. This point was also emphasized by the fact that a considerable percentage of consumers $(32.8 \%)$ did not select a third priority other than expiry and manufactory dates.

More attention was given to the special characteristics stated such as low calories and low cholesterol. This coincides with the increased importance given to decrease weight and fight obesity and related diseases. This requires food producers to know the consumer's needs and preference. They have to seek help from nutritionists to satisfy consumer's need for purchasing a healthy prepackaged food.

Consumers also paid attention to the country of manufacturing and this indicates their concern about buying their food from preferred sources. As more attention is given nowadays to the presence of food additives; more consumes are becoming concerned. This requires more attention by the nutritionists to make this issue understandable and though consumers can be able to make their best choices.

Less attention was given to the content of the package; and as some consumers may want to know what the food package includes; this has to be indicated by nutritionists to raise the awareness level and satisfy the consumers' need for meaningful information.

With the increased interrelationship between food and health; there is always a need for cooperation between organizations and people concerned to explain this relation to consumers and raise their nutritional awareness. To ensure prevention aspects of food; nutritional awareness will always be the cheapest and best solution.

\section{Conclusions and recommendations}

The study assessed the UAE consumers' knowledge; attitude and practices towards food labeling and the information they would like to see on the label for the first time. Although significant correlations were found between single items on the food label and some of the demographic variables; the overall knowledge of the consumers did not show significant correlation with the overall level of education of the consumers in this study. A lot of work is needed to raise the level of awareness of the consumers about the nutrition aspects of the food labeling in order to assist them to make their best healthy food choices.

Hence; the study recommended further studies on the impact of different forms of labeling on the consumer's ability to make use of the information on them. As well, an evaluation for the existing nutrition awareness programs and specifying needs for extension programs in nutrition and food label are also needed.

\section{Acknowledgements}

I would like to acknowledge the Research Affairs at UAEU for their financial support to carry this study.

\section{References}

Al Tamimi \& Company (2004). Standardization and Classification in the UAE. Retrieved from Center for Food safety (2006). Benefits of Nutrition Information on Food Labels. [Online] Available: http://www.cfs.gov.hk/english/programme/programme_nifl/programme_nifl_02.html

AMEinfo.com (2008). Dubai Municipality applies new specifications for food stuff label and GCC validity period rules - Press release. [Online] Available: http://www.ameinfo.com/144611.html

Blanchfield (2000). Food Labeling. Woodhead Publishing. [Online] Available: http://www.cfs.gov.hk/english/programme/programme_nifl/programme_nifl_02.html

Emirates Standardization and Metrology Authority. Labeling of prepackaged foodstuffs. UAE.S/GSO 9/2007. ICS: 67.040.00. [Online] Available: https://www.esma.ae/e-store/default/ICSStandards.aspx?id=668
Gian
Report
TC8030.
(2008).
[Online]
Available:

http://www.gain.fas.usda.gov/.../FAIRS\%20Country\%20Report_Dubai

Godwin, S. L., Speller, H. L., and Thompson, C. (2006). Evaluating the nutrition label: its use in and impact on purchasing decisions by consumers. Journal of Food Distribution Research, 37, (1).

Hawkes. (2004). Nutrition Labels and health claims: the global regulatory environment, WHO. [Online] Available: http://whqlibdoc.who.int/publications/2004/9241591714.pdf 
Himbachi, J. T., \& Stokes, R. C. (2003). Nutrition labeling and public health: Survey of American Institute of nutrition members, food industry and Consumers. American Journal of Clinical Nutrition, 96, 700 - 708. [Online] Available: http://www.jheimbach.com/published.html

Levy, S., Feins, S. B., and Schucker, R. E. (2001). More effective nutrition label formats are not necessarily preferred. Journal of the American Dietetic Association, 92 (10), 1230 - 1234.

McLean, P. E. (2001). An analysis of nutritional label use in the Southern United States. Journal of Food Distribution Research, Food Distribution Research Society, vol. 32 (1).

Saltos, E., Welsh, S., and Davis, C. (1994). The new food label as a tool for healthy eating. Nutrition Today, 29 (3), 18 - 22. http://dx.doi.org/10.1097/00017285-199405000-00006

Springer (2008). A theoretical and empirical investigation of nutritional label use, Berlin / Heidelberg (Electronic version 1618-7598). The European Journal of Health Economics, 9 (3).

Washi, S. (2002). Knowledge, attitudes and practices of Saudi consumers on food labeling. Arab Nutrition Journal, 6, 23-31. Center for Studies and Research, Bahrain.

Washi, S. A. (2001). Nutritional aspects of food labeling in Saudi Arabia. Ahfad Journal, 18 (2), 17-29.

Whitney, E., \& Rolfes, S. R. (2005). Understanding Nutrition (10 ${ }^{\text {th }}$ ed.). WADS Worth; 55, 61.

WHO/FAO. (2003). WHO/FAO Diet, Nutrition and the prevention of chronic diseases. [Online] Available: http://www.fao.org/docrep/008/y7867e/y7867e02.htm \# bm02,

Yetley, E.A., and Lewes, C. J. (1992). Focus group sessions on formats on nutrition labels. Journal of the American Dietetic Association, 92 (1), 62 - 66.

$\mathrm{http}: / / \mathrm{www}$. alain/population, 2009/html

http://www.reportbuyer.com, 2007 
Table 1. Demographic characteristics of the sample $(n=1200)$

\begin{tabular}{|l|c|c|}
\hline Variables & Frequency & Percent \\
\hline Gender & & 54.3 \\
Female & 652 & 45.7 \\
Male & 548 & 68.0 \\
\hline Nationality & & 31.7 \\
Non UAE & 816 & .3 \\
UAE & 380 & \\
Missing & 4 & 69.5 \\
\hline Education & & 30.5 \\
University & 834 & \\
Non University & 366 & 13.6 \\
\hline Occupation & 163 & 34.7 \\
Student & 416 & 14.1 \\
Government & 169 & 17.0 \\
Business & 204 & 15.6 \\
Professional & 187 & 3.8 \\
Housewife & 46 & 1.3 \\
Retired & 15 & \\
Others & & 26.3 \\
\hline Social Status & 316 & 67.9 \\
Single & 815 & 4.1 \\
Married & 49 & 1.4 \\
Divorced & 17 & .1 \\
Widow & 1 & 73.1 \\
Missing & & 26.9 \\
\hline Having Children & 877 & \\
Yes & 323 & \\
No & & \\
\hline
\end{tabular}

Note: A little over half of the consumers interviewed were females (54.3\%). Less than one third (31.7\%) of the shoppers approached were Emiratis as many have declined to be interviewed. Over two thirds $(69.5 \%)$ are having university education or higher and over one third (34.7\%) are government employee. And over two thirds are married (67.9\%) with $73.1 \%$ having children. 
Table 2. Information on food labels according to the consumer's preferences $(n=1200)$

\begin{tabular}{|c|c|c|c|c|c|c|}
\hline & \multicolumn{2}{|c|}{ First importance } & \multicolumn{2}{|c|}{ Second Importance } & \multicolumn{2}{|c|}{ Third Importance } \\
\hline & $\mathrm{F}$ & $\%$ & $\mathrm{~F}$ & $\%$ & $\mathrm{~F}$ & $\%$ \\
\hline Expiry date & 468 & 39.0 & 324 & 27.0 & 82 & 6.8 \\
\hline Manufactory date & 324 & 27.0 & 94 & 7.8 & 29 & 2.4 \\
\hline Not mentioned & 156 & 13.0 & 164 & 13.7 & 193 & 16.1 \\
\hline $\begin{array}{l}\text { Presence of nutritional } \\
\text { label }\end{array}$ & 45 & 3.8 & 82 & 6.8 & 60 & 5.0 \\
\hline Special characteristics & 39 & 3.3 & 111 & 9.3 & 101 & 8.4 \\
\hline Presence of food additives & 39 & 3.3 & 64 & 5.3 & 139 & 11.6 \\
\hline Country of manufacturing & 39 & 3.3 & 68 & 5.7 & 150 & 12.5 \\
\hline Content of package & 25 & 2.1 & 64 & 5.3 & 123 & 10.3 \\
\hline Health warning & 15 & 1.3 & 36 & 3.0 & 98 & 8.2 \\
\hline instruction for preparation & 14 & 1.2 & 40 & 3.3 & 66 & 5.5 \\
\hline Health claim & 12 & 1.0 & 38 & 3.2 & 75 & 6.3 \\
\hline $\begin{array}{l}\text { Presence of info for } \\
\text { special use }\end{array}$ & 12 & 1.0 & 34 & 2.8 & 43 & 3.6 \\
\hline Package size & 8 & 0.7 & 36 & 3.0 & 35 & 2.9 \\
\hline Other & 4 & 0.3 & 4 & 0.3 & 4 & 0.3 \\
\hline
\end{tabular}

Note: Nearly three quarters of the sample (72.8\%) mentioned expiry date as their first, second or third important information they look for in the label. On the other hand, nutrition information is of interest to only about $15 \%$ of the sample reflecting low awareness of the sample about the presence of such information in the label.

Table 3. Information that consumers want to see on Food labels $(n=1200)$

\begin{tabular}{|l|c|c|c|c|}
\hline \multirow{2}{*}{ Food label Information } & \multicolumn{2}{|c|}{ Yes } & \multicolumn{3}{c|}{ No } \\
\cline { 2 - 5 } & F & $\%$ & F & 81.1 \\
\hline Manufactory and expiry date & 227 & 18.9 & 973 & 90.8 \\
\hline Nutritive values of the food & 110 & 9.2 & 1090 & 88.6 \\
\hline Health claims and health warning & 137 & 11.4 & 1063 & 21.2 \\
\hline All of the above & 706 & 58.8 & 494 & \\
\hline
\end{tabular}

Note: When the presence of 13 types of information in the food label were highlighted to consumers, more than half of them wants to see all of them in the food label.

Table 4. Consumer's level of awareness on the importance of the food label $(n=1200)$

\begin{tabular}{|l|c|c|c|c|c|c|}
\hline $\begin{array}{l}\text { Level of } \\
\text { awareness }\end{array}$ & \multicolumn{3}{|c|}{ Male } & \multicolumn{2}{c|}{ Female } & $\%$ \\
\hline & F & $\%$ & F & $\%$ & F & $\%$ \\
\hline High & 102 & 18.61 & 154 & 23.62 & 256 & 21.33 \\
\hline Middle & 227 & 41.42 & 277 & 42.48 & 504 & 42 \\
\hline Low & 219 & 39.96 & 221 & 33.89 & 440 & 36.67 \\
\hline Total & 548 & 99.99 & 652 & 99.99 & 1200 & 100 \\
\hline
\end{tabular}

Note: Computing an awareness score for the sample responses has resulted in a lower score for over one third of the sample $(36.67 \%)$. 
Table 5. Consumer's level of awareness on the importance of the food label according to their education $(\mathrm{n}=1200)$

\begin{tabular}{|l|c|c|c|c|c|c|}
\hline $\begin{array}{l}\text { Level of } \\
\text { awareness }\end{array}$ & \multicolumn{2}{|c|}{ University } & \multicolumn{2}{c|}{ Non- university } & \multicolumn{2}{c|}{ Total } \\
\hline & F & $\%$ & F & $\%$ & F & $\%$ \\
\hline High & 160 & 21.3 & 96 & 31.1 & 256 & 21.3 \\
\hline Middle & 387 & 51.6 & 116 & 37.5 & 503 & 41.9 \\
\hline Low & 203 & 27.1 & 97 & 31.4 & 300 & 25.0 \\
\hline Missing & 141 & & & & & 11.8 \\
& & & & & 1059 & 88.2 \\
Total & 750 & & 309 & & 1200 & 100 \\
\hline
\end{tabular}

Note: Despite the higher level of education for over two thirds of the sample (69.7\%), nearly have (41.9\%) scored middle for the awareness scored computed.

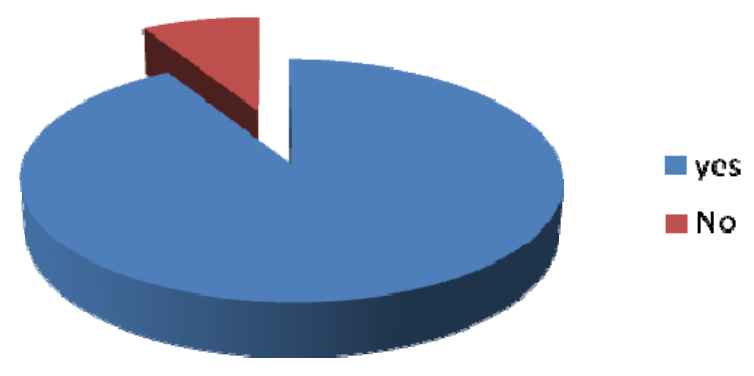

Figure 1. Consumer interest in buying prepackaged food

Note: $91.6 \%$ of the consumers interviewed buy prepackaged foods

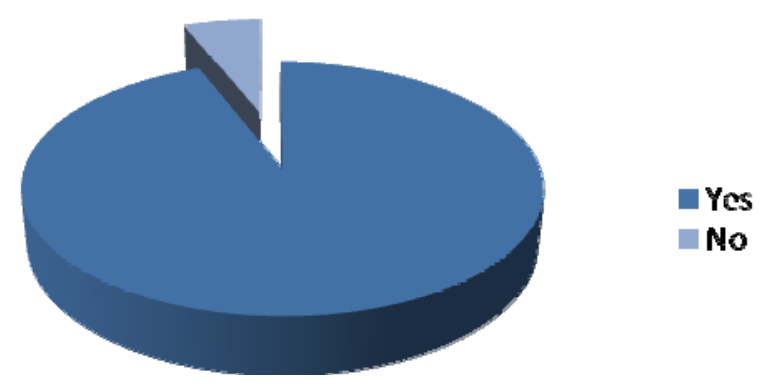

Figure 2. Consumer's interest in reading nutritional information

Note: $89.5 \%$ of the sample read the food label 


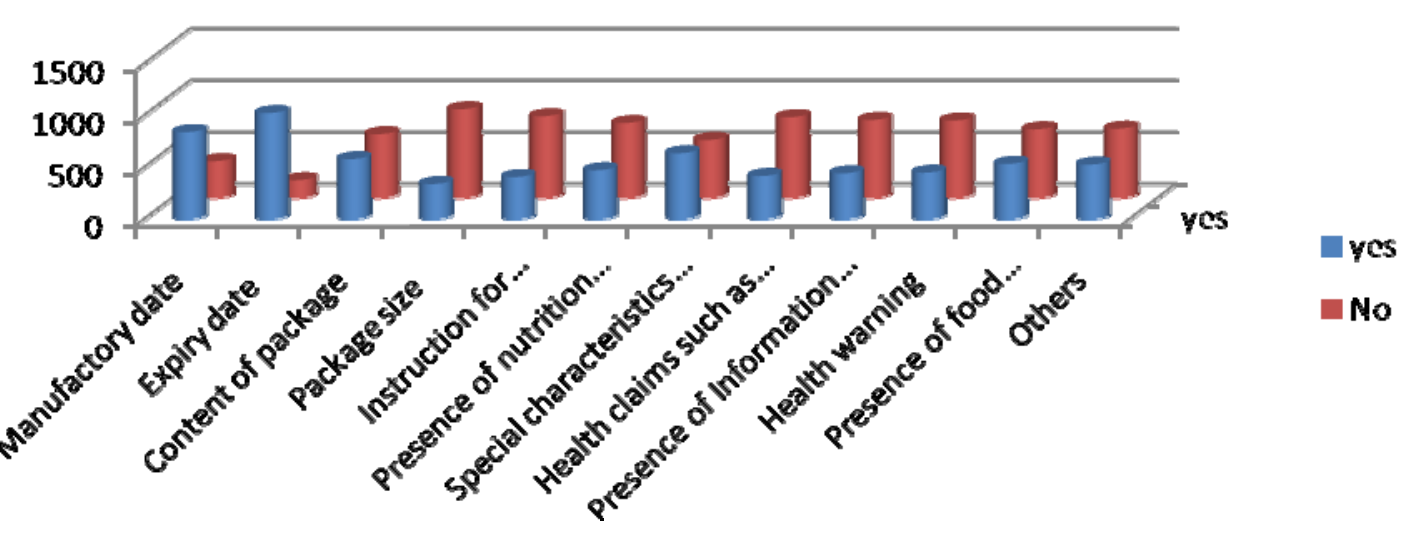

Figure 3. Information that consumers are looking for on the food

Note: $85.6 \%$ look the information about expiry dates while $70.3 \%$ look for production dates. Around $53.3 \%$ want to see special characteristics; $48.5 \%$ look for package contents; while package size was the least important for them as well as instructions for preparation. 